\title{
Trends in sales weighted tar, nicotine, and carbon monoxide yields of UK cigarettes
}

\author{
M J Jarvis
}

\begin{abstract}
Background-Reducing tar yields of manufactured cigarettes has been an important plank of government policy on tobacco, but sale weighted yields are not routinely published.

Methods-Tar, nicotine, and carbon monoxide yields measured by the Laboratory of the Government Chemist were combined with cigarette brand market shares from national surveys of smoking behaviour to generate sales weighted yield estimates for the period 1972-99.

Results-Sales weighted mean tar yields have declined steadily and in 1999 were $9.6 \mathrm{mg}$ per cigarette, less than half their level in 1972. Over the same period nicotine yields have come down from $1.33 \mathrm{mg}$ to $0.79 \mathrm{mg}$ per cigarette. Carbon monoxide yields have shown smaller declines. At the same time as absolute yields have declined, there have also been changes in tar to nicotine ratios. Smokers in 1999 were exposed to $22 \%$ less tar per unit of nicotine than in 1973, and smokers of low tar brands have consistently been exposed to less tar per unit of nicotine than smokers of other brands.

Conclusions-The value of reducing cigarette tar and nicotine yields has been questioned, since the tendency of smokers to compensate for reductions in nicotine delivery undermines the policy. The favourable trends in tar to nicotine ratios suggest that, despite this, there may have been some modest public health benefit. It cannot be assumed that future reductions from present levels would necessarily result in further improvement in tar to nicotine ratios. An explicit focus on the ratio of tar to nicotine may provide a metric of greater relevance for public health than the present emphasis on absolute tar yields.

(Thorax 2001;56:960-963)
\end{abstract}

Keywords: cigarette smoking; tar to nicotine ratio; tar; nicotine; carbon monoxide

For the past 25 years there has been a policy of gradually reducing the tar yields of manufactured cigarettes on sale in the UK. ${ }^{1}$ This policy was pursued initially through a series of voluntary agreements between government and the tobacco industry, and more recently through European Union directives. ${ }^{2}$ The directive currently in force limits tar yields as measured on smoking machines by ISO methods to $12 \mathrm{mg}$ per cigarette; a new directive which has recently been agreed imposes a tar limit of
$10 \mathrm{mg}$ per cigarette and, for the first time, introduces limits on nicotine $(1 \mathrm{mg}$ per cigarette) and carbon monoxide (10 mg per cigarette). The policy of lowering cigarette yields is predicated on the assumption that this will result in lowered exposure among smokers to toxic combustion products, and hence may contribute to a reduction in risk of smoking related disease. This has come under increasing question as evidence has accumulated that smokers' intakes are driven primarily by their need to regulate nicotine intake, and that machine smoked cigarette yields predict measured exposure weakly, if at all. ${ }^{34}$

Putting to one side the question of the public health value of the low tar programme, it is of interest to examine how successful it has been in achieving declines in nominal yields and what challenges there may be to achieving the new targets for nicotine and carbon monoxide deliveries. To do this requires monitoring of the yields of cigarette brands to which smokers are exposed. A simple arithmetic mean of yields may not be informative as there is a proliferation of brands (over 240 in 1999), with many having negligible sales while a few predominate. In order to estimate the exposure of the smoking population, the yield figures need to be weighted according to the market shares of the brands on sale. The Tobacco Manufacturers' Association supplies sales weighted yield information to the Department of Health based on internal industry estimates of brand market share combined with yield figures from the Laboratory of the Government Chemist, but these data are not published. In previous papers ${ }^{5}{ }^{6}$ it was shown that reliable estimates can be constructed using brand market share figures from national surveys of smoking behaviour, and figures were given for the years from 1972 to 1985 . The present paper extends these estimates up to 1999 , using data from the General Household Survey to derive brand shares, and comments on the figures.

\section{Methods}

Tar, nicotine, and carbon monoxide yields of manufactured cigarettes were taken from surveys conducted on behalf of the government by the Laboratory of the Government Chemist (LGC) since 1972. Before 1991 the LGC used a UK specific definition of butt length which resulted in slightly higher yields than the ISO methods. There were also changes to the way nicotine was measured in 1991 which resulted in a decline of about $5 \%$ in measured values, or $0.05 \mathrm{mg} /$ cigarette for a mean yield of $1 \mathrm{mg}$. Since 1991 the UK methods have conformed to published ISO standards. ${ }^{7-9}$ LGC conducted
1 August 2001

Accepted for publication

2 August 2001 
Table 1 Sales weighted mean tar, nicotine, and carbon monoxide yields (mg/cigarette) of UK manufactured cigarettes 1972-99

\begin{tabular}{|c|c|c|c|c|c|c|c|c|c|c|}
\hline \multirow{2}{*}{$\begin{array}{l}L G C \\
\text { survey }\end{array}$} & \multirow[b]{2}{*}{ Date } & \multicolumn{3}{|c|}{ Plain cigarettes } & \multicolumn{3}{|c|}{ Filter cigarettes } & \multicolumn{3}{|c|}{ All cigarettes } \\
\hline & & Tar & Nicotine & $\mathrm{CO}$ & Tar & Nicotine & $C O$ & Tar & Nicotine & $C O$ \\
\hline 1 & Jul 72-Dec 72 & 28.6 & 1.86 & & 19.0 & 1.23 & & 20.5 & 1.33 & \\
\hline 2 & Jun $73-$ Nov 73 & 24.7 & 1.63 & & 17.7 & 1.15 & & 18.7 & 1.22 & \\
\hline 3 & Jan 74-Jun 74 & 25.7 & 1.72 & & 17.5 & 1.15 & & 18.4 & 1.22 & \\
\hline 4 & Aug 74-Jan 75 & 25.3 & 1.74 & & 17.9 & 1.19 & & 19.0 & 1.27 & \\
\hline 5 & Mar 75-Aug 75 & 25.0 & 1.87 & & 17.7 & 1.23 & & 18.6 & 1.30 & \\
\hline 6 & Oct $75-$ Mar 76 & 25.1 & 1.88 & & 17.2 & 1.16 & & 18.2 & 1.25 & \\
\hline 7 & May $76-$ Oct 76 & 25.1 & 2.02 & & 16.5 & 1.22 & & 17.4 & 1.31 & \\
\hline 8 & Dec 76-May 77 & 24.9 & 2.05 & & 16.3 & 1.25 & & 17.1 & 1.33 & \\
\hline 9 & Jul 77-Dec 77 & 24.9 & 1.97 & & 16.4 & 1.20 & & 17.3 & 1.28 & \\
\hline 10 & Feb 78-Jul 78 & 24.1 & 2.00 & 13.4 & 16.7 & 1.30 & 16.3 & 17.2 & 1.36 & 16.1 \\
\hline 11 & Sep $78-$ Feb 79 & 20.3 & 1.64 & 11.0 & 16.7 & 1.33 & 16.5 & 17.0 & 1.36 & 16.0 \\
\hline 12 & Apr 79-Sep 79 & 19.0 & 1.57 & 11.0 & 16.1 & 1.33 & 16.2 & 16.3 & 1.34 & 15.9 \\
\hline 13 & Nov 79-Apr 80 & 18.7 & 1.48 & 11.3 & 16.6 & 1.34 & 16.8 & 16.8 & 1.35 & 16.4 \\
\hline 14 & Jun $80-$ Nov 80 & 18.4 & 1.41 & 11.3 & 15.8 & 1.28 & 16.5 & 16.0 & 1.28 & 16.0 \\
\hline 15 & Jan 81-Jun 81 & 18.6 & 1.50 & 10.7 & 15.4 & 1.31 & 15.1 & 15.6 & 1.32 & 14.8 \\
\hline 16 & Aug $81-$ Jan 82 & 18.5 & 1.44 & 11.0 & 15.3 & 1.28 & 15.2 & 15.5 & 1.29 & 14.9 \\
\hline 17 & Mar 82-Aug 82 & 18.4 & 1.51 & 11.7 & 15.2 & 1.31 & 15.6 & 15.4 & 1.32 & 15.4 \\
\hline 18 & Oct $82-$ Mar 83 & 18.4 & 1.50 & 11.4 & 15.2 & 1.30 & 15.0 & 15.4 & 1.31 & 14.8 \\
\hline 19 & May $83-$ Oct 83 & 18.3 & 1.47 & 11.8 & 14.4 & 1.26 & 14.3 & 14.6 & 1.27 & 14.3 \\
\hline 20 & Dec 83-May 84 & 17.7 & 1.34 & 11.2 & 14.8 & 1.30 & 14.3 & 14.9 & 1.30 & 14.2 \\
\hline 21 & Jul 84-Dec 84 & 17.4 & 1.34 & 11.2 & 14.2 & 1.26 & 13.7 & 14.4 & 1.26 & 13.6 \\
\hline 22 & Feb 85-Jul 85 & 17.1 & 1.39 & 11.0 & 13.9 & 1.25 & 14.2 & 14.1 & 1.26 & 14.1 \\
\hline 23 & Sep 85-Feb 86 & 17.5 & 1.48 & 11.2 & 13.8 & 1.29 & 14.3 & 14.0 & 1.30 & 14.2 \\
\hline 24 & Apr $86-$ Sep 86 & 17.1 & 1.47 & 11.3 & 13.3 & 1.27 & 14.3 & 13.5 & 1.27 & 14.2 \\
\hline 25 & Nov 86-Apr 87 & 17.3 & 1.49 & 11.1 & 13.4 & 1.26 & 13.9 & 13.5 & 1.27 & 13.6 \\
\hline 26 & Jun $87-$ Nov 87 & 17.1 & 1.43 & 11.1 & 13.1 & 1.20 & 13.8 & 13.2 & 1.21 & 13.7 \\
\hline 27 & Jan 88-Jun 88 & 16.7 & 1.35 & 11.1 & 12.9 & 1.16 & 14.0 & 13.0 & 1.16 & 13.9 \\
\hline 28 & Aug 88-Jan 89 & 16.7 & 1.32 & 10.9 & 12.8 & 1.13 & 13.9 & 12.8 & 1.13 & 13.8 \\
\hline 29 & Mar 89-Aug 89 & 16.1 & 1.29 & 10.8 & 12.7 & 1.13 & 14.0 & 12.7 & 1.14 & 13.9 \\
\hline 30 & Oct $89-$ Mar 90 & 16.4 & 1.40 & 10.9 & 12.3 & 1.13 & 13.7 & 12.4 & 1.13 & 13.6 \\
\hline 31 & May $90-$ Oct 90 & 16.6 & 1.38 & 11.3 & 12.3 & 1.14 & 14.1 & 12.4 & 1.15 & 14.0 \\
\hline 32 & Dec 90-May 91 & 16.4 & 1.29 & 11.4 & 12.5 & 1.09 & 14.5 & 12.5 & 1.09 & 14.5 \\
\hline 33 & Jul 91-Dec 91 & 13.8 & 1.06 & 8.9 & 11.3 & 0.95 & 12.4 & 11.4 & 0.96 & 12.3 \\
\hline 34 & Feb 92-Jul 92 & 13.8 & 1.00 & 9.5 & 11.0 & 0.90 & 12.5 & 11.0 & 0.90 & 12.4 \\
\hline 35 & Sep 92-Feb 93 & 14.0 & 0.99 & 9.6 & 11.5 & 0.86 & 12.9 & 11.5 & 0.91 & 12.9 \\
\hline 36 & Apr 93-Sep 93 & 13.7 & 0.95 & 9.3 & 10.9 & 0.85 & 12.3 & 10.9 & 0.86 & 12.3 \\
\hline 37 & Nov 93-Apr 94 & 13.7 & 0.96 & 9.2 & 10.9 & 0.85 & 12.5 & 11.0 & 0.85 & 12.5 \\
\hline 38 & Jun $94-$ Nov 94 & 13.4 & 0.92 & 9.3 & 10.6 & 0.83 & 12.2 & 10.6 & 0.83 & 12.2 \\
\hline 39 & Jan 95-Dec 95 & 13.7 & 0.95 & 10.2 & 10.4 & 0.85 & 12.1 & 10.4 & 0.85 & 12.1 \\
\hline 40 & Jan 96-Dec 96 & 13.0 & 0.89 & 9.5 & 10.3 & 0.84 & 11.8 & 10.3 & 0.84 & 11.8 \\
\hline 41 & Jan 97-Dec 97 & 13.1 & 0.94 & 9.1 & 10.1 & 0.80 & 11.5 & 10.1 & 0.80 & 11.5 \\
\hline 42 & Jan 98-Dec 98 & 12.1 & 0.89 & 8.3 & 9.7 & 0.78 & 11.0 & 9.7 & 0.78 & 11.0 \\
\hline 43 & Jan 99-Dec 99 & 12.5 & 0.96 & 8.3 & 9.5 & 0.79 & 11.1 & 9.6 & 0.79 & 11.1 \\
\hline
\end{tabular}

Note: Brand market share estimates derived from NOP surveys 1972-85 and from General Household Survey since 1986.

two surveys a year until the end of 1994, but since then each survey has covered a full calendar year. For the years up to 1985 brand shares were derived from surveys carried out by National Opinion Polls (NOP) on behalf of the Office of Population Censuses and Surveys. ${ }^{6}$ Since 1986 the General Household Survey (GHS) has included a question on brand smoked in its coverage of smoking habits. The GHS is a continuous cross sectional survey of

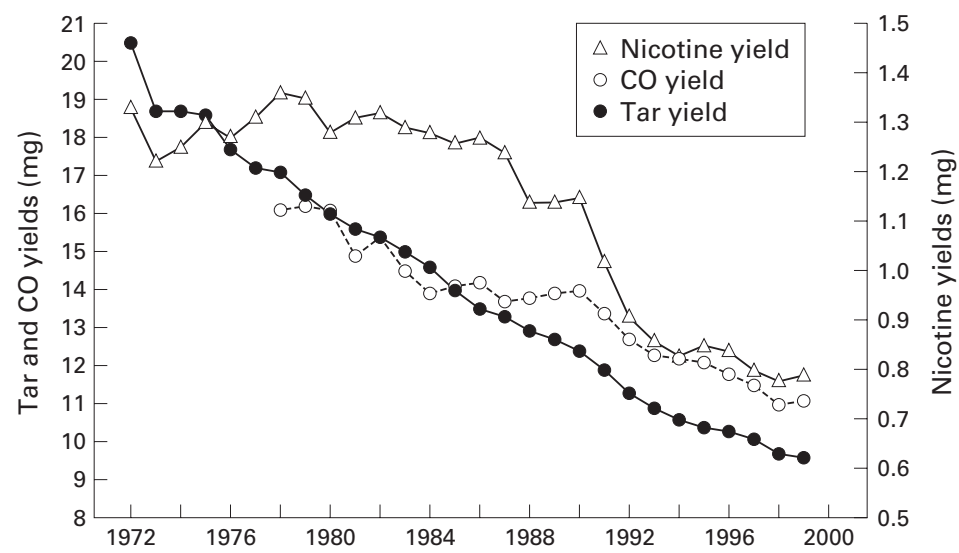

Figure 1 Sales weighted mean tar, nicotine, and carbon monoxide yields (mg/cigarette) of UK manufactured cigarettes 1972-99. individuals in Great Britain living in private households. It is the principal source of official figures on adult smoking and includes smoking questions every 2 years. The GHS provides a sample of some 5000 adult cigarette smokers each year. On the assumption that smokers of different brands smoke on average the same number of cigarettes, the declared brand preferences should reflect current market shares. Estimates of sales weighted yields derived from combining GHS market share estimates with LGC yield figures have been compared with the unpublished industry estimates supplied to the Department of Health. The level of agreement is extremely close.

\section{Results}

Sales weighted yields since 1972 are shown in table 1 and fig 1 . There has been a steady decline in tar yields over the whole period since 1972 from a sales weighted mean of $20.5 \mathrm{mg}$ per cigarette in 1972 to $9.5 \mathrm{mg}$ per cigarette in 1999. The latter figure is already comfortably below the limit of $10 \mathrm{mg}$ which is to be introduced throughout the EU by 2002 .

Nicotine yields, for which there have not been any explicit targets until now, have displayed a somewhat different pattern. There was little change between the early 1970s and about 1986, with nicotine yields averaging about $1.3 \mathrm{mg}$ per cigarette. Over the next few years there was a substantial decline to $<1 \mathrm{mg}$ per cigarette, only a small part of which was attributable to the measurement changes introduced in 1991. Since 1994 the decline has continued, but at a much reduced rate, so that by 1999 the sales weighted mean had reached $0.79 \mathrm{mg}$ per cigarette. As with tar, this is already comfortably below the $1 \mathrm{mg}$ target due to be introduced within the EU in the next year or so.

Data for carbon monoxide are available only since 1978. CO yields initially declined from similar levels and at much the same rate as tar yields, but since the mid 1980s there has been increasing divergence. Sales weighted CO yields in 1999 averaged $11.1 \mathrm{mg}$, some $10 \%$ higher than the proposed EU limits.

It has been suggested that smokers' intakes from cigarettes are driven by their need to maintain preferred levels of blood nicotine. ${ }^{3}$ The strong version of this argument is that compensation for changes in nicotine yield may be complete. If this is the case, interest shifts from absolute tar and nicotine yields to the ratio of tar and nicotine deliveries since, if smokers maintain nicotine intakes irrespective of nominal nicotine deliveries, it is the amount of tar generated per unit of nicotine that will determine the relative amount of tar exposure in smokers of different brands (C Bates, unpublished, 2001). Figure 2 shows changes in tar to nicotine ratios from 1973 to 1999 . At the beginning of this period sales weighted tar to nicotine ratios averaged 15.4. Throughout the 1970s and early 1980s they declined steadily, reaching a low of 10.6 in 1986 . There was then an increase to over 12.5 but, over the past 5 years, the ratio has held steady at around 12 . Sales weighted mean tar to nicotine ratios were 


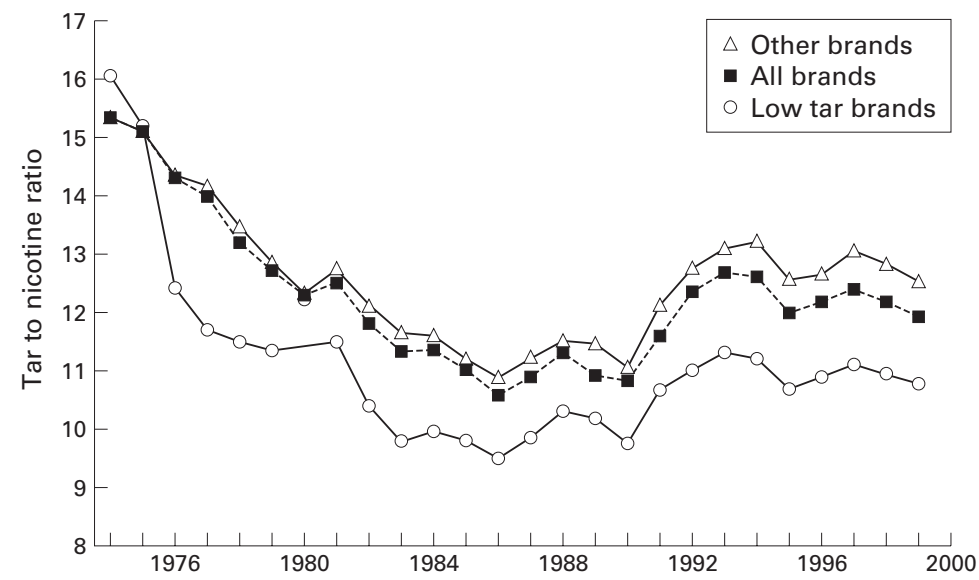

Figure 2 Sales weighted mean tar to nicotine ratios in low tar brands, other brands, and all brands combined.
Whether the tar reduction policy has been of benefit in reducing smoking related disease has been the subject of debate. Epidemiological evidence has been interpreted as showing benefits both for low tar smokers compared with higher tar smokers and for smokers of filter compared with plain cigarettes, ${ }^{13}{ }^{14}$ and for time trends of smoking related disease in a population as yields reduce..$^{15}$ Against this has been the compelling evidence for nicotine compensation, with cigarette nicotine yields explaining little if any of the variance of nicotine intakes in smokers. ${ }^{34}$ These human exposure data indicate that the absolute reductions in tar yields have few implications for inhaled smoke dose in smokers. Interestingly, the yield figures point to a benefit for smokers both if the yield data are true indicators of exposure and if nicotine compensation dominates. In the latter case tar to nicotine ratios have improved by about $20 \%$ over the years (which should impact on time trends for smoking related diseases), and low tar smokers have consistently experienced a reduction in tar to nicotine ratio of about $14 \%$ compared with smokers of higher yielding brands. This is about the extent of risk reduction in low tar smokers which many epidemiological studies have observed. ${ }^{1416}$

It is interesting to note that, although smokers of manufactured cigarettes have apparently fairly easily adapted to the gradual lowering of yields over the years, at any particular point in time brands at the higher end of available yields have dominated the market. Brands yielding $4 \mathrm{mg}$ or less tar have never commanded a significant market share. How low mean yields could go before provoking major consumer resistance is uncertain. Given that, with current cigarette designs, smokers can achieve high nicotine intakes whatever the nominal yield of the cigarette, it is likely that consumer resistance would be fuelled more by the effort required to generate the desired dose than any actual limitation on delivery. Only if the absolute bioavailability of nicotine was restricted, as has been advocated, ${ }^{17}$ would the real limits to acceptable doses become apparent.

The data presented here for sales weighted tar, nicotine, and carbon monoxide yields provide up to date information on the UK market. They correspond closely with unpublished figures supplied to the government by the Tobacco Manufacturers' Association, but have the merit of being based on publicly available sources and have the potential to be updated in the future. Whether the low tar programme has run its course as a useful means of regulating emissions of manufactured cigarette is subject to an ongoing debate, with strong arguments that the yield figures serve only to mislead both consumers and regulators. ${ }^{18}$ Whatever view is taken of the merits of the strategy of tar reduction, the sales weighted yield data will continue to be of use in documenting what that programme has delivered. 
1 Waller RE, Froggatt P. Product modification. $\mathrm{Br}$ Med Bull 1996;52:193-205.

2 Bates C, McNeill A, Jarvis MJ, et al. The future of tobacco product regulation and labelling in Europe: implications for the forthcoming European Union directive. Tobacco Control 1999;8:225-35.

3 Royal College of Physicians. Nicotine addiction in Britain. London: Royal College of Physicians, 2000.

4 Jarvis MJ, Primatesta P, Boreham R, et al. Nicotine yield from machine-smoked cigarettes and nicotine intakes in smokers: evidence from a representative population survey. 7 Natl Cancer Inst 2001;93:134-8.

5 Jarvis MJ, Russell MAH. Tar and nicotine yields of UK cigarettes 1972-1983: sales-weighted estimates from nonindustry sources. Br $\mathcal{F}$ Addiction 1985;80:429-34.

6 Jarvis MJ, Russell MAH. Sales-weighted tar, nicotine and carbon monoxide yields of UK cigarettes: 1985. Br $\mathcal{F}$ carbon monoxide yields
Addiction 1986;81:579-81.

7 International Standards Organisation. Determination of total and nicotine-free dry particulate matter using routine analytical and nicotine-free dry particulate matter using routine analytical
smoking machine. Standard 4387. Geneva: International smoking machine. Standard 4387
Standards Organisation, 1991.

8 International Standards Organisation. Determination of water in smoke condensate of cigarettes (gas-chromatographic method). Standard 10362-1. Geneva: International Standards Organisation, 1991

9 International Standards Organisation. Determination of nicotine in smoke condensate of cigarettes (gas-chromatographic method). Standard 10315. Geneva: International Standards Organisation, 1991.

10 Forey B, Lee P, Fry J. Updating UK estimates of age, sex and period specific cumulative constant tar cigarette consumption per adult. Thorax 1998;53:875-8.
11 Wald N, Doll R, Copeland G. Trends in tar, nicotine, and carbon monoxide yields of UK cigarettes manufactured since 1934. BMF 1981;282:763-5.

12 Kozlowski LT, Mehta NY, Sweeney CT, et al. Filter ventilation and nicotine content of cigarettes from Canada, the United Kingdom, and the United States. Tobacco Control 1998;7:369-76.

13 Stellman SD. Cigarette yield and cancer risk: evidence from case-control and prospective studies. In: Zaridze DG, Peto $\mathrm{R}$, eds. Tobacco: a major international health hazard. IARC Scientific Publications No 74. Lyon: International Agency for Research on Cancer, 1986:197-209.

14 Tang JL, Morris JK, Wald NJ, et al. Mortality in relation to tar yield of cigarettes: a prospective study of four cohorts. BMf 1995;311:1530-3.

15 Peto R. Overview of cancer time-trend studies in relation to changes in cigarette manufacture. In: Zaridze DG, Peto R, eds. Tobacco: a major international health hazard. IARC Scientific Publications No 74. Lyon: International Agency for Research on Cancer, 1986:211-26.

16 Parish S, Collins R, Peto R, et al. Cigarette smoking, tar yields, and non-fatal myocardial infarction: 14000 cases and 32000 controls in the United Kingdom. BMf 1995;311:471-7.

17 Benowitz NL, Henningfield JE. Establishing a nicotine threshold for addiction: the implications for tobacco regulation. N Engl f Med 1994;331:123-5.

18 NCI Expert Committee. The FTC cigarette test method for determining tar, nicotine and carbon monoxide yields of US cigarettes. Smoking and Tobacco Control Monograph 7. National Cancer Institute, 1996. 